\title{
Sustainability Challenges in an Urban Century: Can We Change Urbanization Paths to Make Cities the Solutions for Rather than the Drivers of Global Problems?
}

\author{
Jose A. Puppim de Oliveira \\ Fundação Getulio Vargas (FGV), São Paulo School of Management (EAESP) and Brazilian School of Public and \\ Business Administration (EBAPE), São Paulo, SP, Brazil; E-Mail: jose.puppim@fgv.br
}

Published: 15 March 2019

Is urbanization a danger or a solution to global sustainability? What institutions need to change to make urban areas more sustainable? In examining urbanization rates in countries over time, we see that they are often more correlated to carbon dioxide emissions than per capital income [1]. This tells us that urbanization patterns of the last 100 years have contributed to the increase in carbon emissions. We therefore need to develop a new kind of urbanization in order to tackle global challenges. However, reports about global changes often portray urbanization as "a problem". Cities are polluted and increasingly crowded; urban inhabitants consume proportionately more resources and are responsible for a large portion of carbon emissions ([2], p. 927). As a urban planner, when I read those reports it seems I am looking at the books of urban planning in the last century, particularly those on urbanization in the colonies, where urbanization was presented as an unwanted process that caused a lot of harms to the "civilization" $[3,4]$. We must therefore change the discourse on how we describe urbanization if we want to transform it, as it will not be stopped. We must stress the many benefits that urbanization has brought to society, which are the main reasons people want to come to the cities in the first place. A question to be considered is therefore how to make urban life compatible with global challenges? i.e., how can we continue implementing/developing urbanization and the benefits that come with it without disproportionally increasing carbon emissions, the destruction of ecosystems and unsustainable consumption. There are many opportunities for win-win strategies between global sustainability challenges and development in urban areas, or synergies, such as climate co-benefits, i.e., tackling climate change and promoting development, particularly in some developing countries where cities are still being built and the path of urbanization can be changed $[5,6]$. Nevertheless, despite all we have learned about urbanization and the possible co-benefits opportunities since the last century, we lack understanding of the contextual and institutional conditions that make those solutions emerge.

Rather than focusing on the contribution to planetary problems that the development of cities' can cause, it would be more productive to frame urbanization as an opportunity leading towards a sustainable future. One characteristic of cities that opens opportunities for solutions is scale and efficiency. Urban areas constituted less than $2 \%$ of the worlds land surface area in the beginning of this century according to some estimates; however, these confined spaces are key centers of production and consumption [7]. Activities are concentrated in a small space, making some solutions (such as public transportation and district heating systems) more viable as compared to dispersed settlements. Cities are also centers of knowledge, vast financial resources and decision-making, which can catalyze changes, quickly leading to a greener economy [8]. For many years, urban experts have believed that the spatial distribution (city form, density and land-use) is the key for determining environmental impacts, including climate change. More recently, however, other additional factors have been deemed important, such as energy use in buildings, transportation and citizens' consumption behaviors. For cities that are growing, linking land-use plan- 
ning to other urban activities is key. Spatial aspects, such as improving green areas to reduce the urban heat island effect or avoiding urban sprawl so public transportation can be more viable, are fundamental in making cities more sustainable. Buildings are another important sector, which, in addition to emissions, are places where a lot of the urban population spends most of their time. Once a building is built in an unsustainable manner, it can stay there for decades. Improving sustainable construction would therefore make significant advancements in cities in the medium and long term [9]. For established cities, improving efficiency in the use of energy in buildings and vehicles and allowing mix land-use should be a priority, as city form is difficult to change when the city is already functioning. Finally, we have the effects of consumption. City dwellers consume large amounts of energy and resources from other regions. Cities are massive drivers of consumption that affect the city within and beyond its boundaries.

\section{Context Matters: Different Cities, Different Challenges, Different Solutions}

The sustainability challenges are different depending on the city, especially between cities in developed countries versus those in developing countries. In developing countries, the key factor in moving forward the development agenda is the link between the various goals of sustainable development in cities. Cities in many of those countries struggle with "old problems", such as provision of services (water, sanitation, energy, etc.), housing and jobs/income/economic opportunities for its citizens, while simultaneously trying to tackle "newer problems" such as climate change [10]. We must therefore urbanize in a different way than the aforementioned developed countries and innovate with win-win situations. For example, if citizens and local authorities find a trade-off between socio-economic development and climate change, they will most likely choose the former. This is explicit in Rio+20 outcomes, as the main document highlights how poverty alleviation/eradication is the main challenge that humanity faces [11]. This is due to, in particular, the pressure of the G77+China group, the block of developing countries, which did not accept any constraints on economic development and framed sustainable development as fighting poverty in the first place.

On the other hand, many cities in developed countries have cleaned up quite a lot in the past few decades. Rivers and air in most cities in wealthy countries are cleaner in terms of local pollutants than they were 50 years ago. However, a large part of this was transferring production (and polluting) activities to developing countries [12]. The largest environmental impacts caused by cities in developed countries are from consumption, which often drives production elsewhere. Citizens in developed countries on average have a much larger consumption footprint. The first step should therefore be to reduce their footprints. Rich countries, for example, could put promoting the Sustainable Development Goal 12 (responsible consumption and production) as a priority in their development agenda by creating specific regulation and economic incentives to reduce their footprints. The second step could be to bear a significant part of the finance of the urban transition of developing countries to generate climate co-benefits, so cities there avoid the unsustainable path [6]. This transition can also generate winners and losers in developed and developing countries. There is a substantial need for investments in the transition toward a greener economy in developing countries to offset the short-term losses of some groups in developing countries, particularly amongst the poor, who might share a large part of the burden, as many get subsidies on electricity from fossil fuel powered plants or artificial fertilizers. Finally, developed countries can help to build up the institutions and some of the technological capabilities developing countries need for the transition.

\section{Cities Leading the Way?}

Rio+20 had a modest outcome, maybe the most relevant being the idea of the Sustainable Development Goals (SDGs) [11], especially compared with our expectations prior to the meeting and the urgency of the Earth's situation. However, one of the most positive outcomes came from cities. Important meetings such as the Urban Nature Forum, C40 and other city meetings showed a high degree of interest and commitment. In Rio+20, several large cities, including New York and Rio, committed to tackling their GHG emissions even without the support of their national governments. The monumental challenge is now implementation, to make the commitments into reality, and to prove that cities can lead the way.

There are many examples of cities that are leading the way with innovative initiatives and commitments. It is difficult to identify a city that is a good example in every aspect of sustainability. Some cities are examples of innovative capacity, such as Curitiba, which has created a good system of public transportation and caused its emissions to be much lower than in similar cities. Moreover, some of its innovations have spread to other cities around the world, such as the Bus Rapid Transit (BRT), which are now established in 170 cities [13]. In Europe, Copenhagen has shown important initiatives, such as the pedestrian districts and the use of non-motorized transportation [14]. Several other cities followed its steps, with pedestrian roads and bicycles returning to many cities. In Japan, Tokyo is leading the world with the first system of cap-and-trade for greenhouse gas (GHG) emissions that also includes buildings [15]. There is also participation in China, where there are commitments from some cities, such as Shanghai, to significantly reduce their emissions by modernizing industries and improving energy and transportation systems. Beijing cleaned up for the Olympics with interesting projects to reduce air pollution and GHG emissions, and many of those projects like the transportation network have since continued to expand [16].

Many of these initiatives aim to promote the idea of sustainability in particular aspects of urban life, some with 
significant achievements and others less comprehensive or sustainable in the long term. Many of the positive changes that have been initiated did not need large investments and were achieved with a short time span. Many of those changes were due to lack of natural resources or local alternatives. For example, many cities in Japan recycle a lot because there is no alternative for disposal except the relatively expensive incinerators. Yokohama has reduced its solid waste by more than $40 \%$ in a decade [17], with significant impacts on GHG emissions. This has been driven by the lack of space and large costs of solid waste management. Others had solutions that were not sustainable. New Delhi, for example, reduced its air pollution significantly in the 2000s, cleaning up polluting modes of transport, although it became heavily polluted again as the number of vehicles and other polluting sources increased despite the development of the metro [18].

\section{Governance and Institutional Challenges}

When dealing with sustainability in cities, there are also many challenges related to the institutions of governance. Cities operate in different institutional environments, which makes the generalization and transfer of knowledge and innovations difficult. A fundamental aspect to consider before any other is the difficulty in defining what a city or urban is. The definition of cities varies among countries, as there is no universallyaccepted definition of urban. Urbanization reports are based on countries' data using their own definition of urban, which varies across administrative, density, population and other criteria. Thus, when we talk about urban areas or cities, we are often talking about different things.

Secondly, the influence of cities in global governance is growing; however, it is still limited. This constrains their ability to influence the agenda and allocation of resources. In the formal negotiations within United Nations Framework Convention on Climate Change (UNFCCC), there was no explicit discussions forums for which cities, as sub-national governments, can express themselves. The negotiations mostly focus on the national level, as the parties in the discussions are all national governments. The first step should therefore be to explicitly recognize the challenges and opportunities involved in tackling global environmental problems in urban areas, as well as the role of local authorities, as some conventions, such as the Convention on Biological Diversity (CBD), have done since 2010 (Decision $X / 22)$. In the UNFCCC, cities participate from the sidelines, represented by groups such as ICLEI or C40, which are regarded as NGOs. Some elected city mayors are not permitted in their country official delegations. They are sometimes forced to attend as NGO members. However, cities are the focus on other forums of discussions on climate change. The reports of the International Panel on Climate Change (IPCC) contain chapters on cities discussing both mitigation and adaptation. The IPCC hosted a conference on cities and climate change in Edmonton, Canada, in March 2018. Cities also organize parallel meet- ings in the UNFCCC COPs and separate events on climate change, such as those organized by ICLEI and C40, where they learn from each other and make commitments to tackle their GHG emissions, which are even more ambitious than the commitments of their countries.

Thirdly, a few cities are countries (like Singapore), others are states/provinces (like Tokyo Metropolitan GovernmentTMG) or local entities at the third or fourth tiers of government. Many cities depend on national governments to advance their sustainability agenda and to make changes in the way urbanization is occurring. If you consider cities as sub-national entities, the situation regarding the degree of involvement and capacity of cities in tackling global and local development issues varies from country to country [19]. In many countries, sub-national governments have large autonomy and control important services that impact climate change, such as transportation, building and land-use. In other countries, sub-national governments are dependent on the national or higher-level governments (like states) for funding and autonomy to make changes. In decisions about important issues that can make a difference, such as green taxes, many cities do not have the autonomy to make changes, or have leakage effects (it does not make sense to impose the carbon taxes on fossil fuels if the city next door does not do the same). Over all, cities can do a lot by themselves, but they could do more if there were better coordinated with national governments, which it is not the case for many countries. For example, urban governance in Malaysia and other Asian countries suffers from the lack of strong institutions for intergovernmental relations to tackle more challenging issues like climate change, meaning that this requires much better coordination within the different levels of government [20].

Finally, the toughest institutional challenge is the engagement of cities beyond megacities and more resourceful cities. It is estimated that there are one million local governments. Even though megacities (considering cities with more than 10 million inhabitants) are important urban conglomerations, much of the urbanization happens in medium-size smaller cities (e.g., between 100,000 and $5,000,000$ inhabitants) [21]. These cities are rarely in the news or participating in the C40 meetings, which focuses on megacities. For example, there are more than one hundred cities with more than one million inhabitants in China. India also has more than 50 urban conglomerations with more than one million inhabitants. In other Asian countries and Africa, urbanization is taking place at a tremendously rapid pace, never seen before. Asia alone is expected to add another one billion people to its cities in the next 20 years, with large impacts on climate change if the urbanization pattern is not sustainable [22]. Thus, the major governance challenge is to bring those medium and small cities into more sustainable tracks, particularly those in rapidly urbanizing developing countries, as they will be fundamental in determining the future of the planet.

Asian and African cities have great potential for change, as many are in countries in which urbanization is occurring 
at a fast pace. There are large opportunities for co-benefits. There is a new push for sustainable cities in Asia, particularly in China, which is due to central decisions to achieve more energy and pollution targets at the local level. We may expect China to achieve its GHG emissions peak before the initial commitment of 2030. Some African cities are modernizing and investing in rail systems, such as Johannesburg metropolitan area, and renewable energy. The hope, therefore, is that we may see a definitive change towards more sustainable cities in Asia and Africa; however, we need to move quickly to understand what makes those sustainable urban solutions emerge in a faster pace in their institutional conditions. The examples we have of sustainable urbanization, particularly in the Western countries, were not able to mainstream solutions to global and local development issues together in their urbanization processes. The solutions to global problems came too late or did not fulfill all, or most, dimensions of development in terms of sustainable use of resources or physical and social conditions.

We can conclude that, on the one hand, there is a need to understand the connections among the SDGs in innova- tive urban interventions to better assess how they advance (or not) with the different dimensions of development in the short, medium and long term. Co-benefits among the various dimensions of development are key to avoid advancing in certain goals and retreating in others, as were the urbanization processes in the past. On the other hand, we need to gather more knowledge about the social, political and institutional conditions that enable different kinds of urban innovations and sustainable urbanization patterns to emerge in the first place, particularly in rapidly urbanizing countries in Asia and Africa, in order to nurture the appearance of those conditions. The multidimensional 2030 Agenda for Sustainable Development, which includes the 17 Sustainable Development Goals (SDGs), could be an opportunity to rethink urbanization patterns. Even though there is one SDG about cities (SDG 11), urbanization processes are related to all of the other goals, as most of the world's population now lives in cities. The achievement of the SDGs is closely related to how we can change our current cities and the new cities of the future.

\section{References and Notes}

[1] Sethi M, Puppim de Oliveira J. From global 'North-South' to local 'Urban-Rural': A shifting paradigm in climate governance? Urban Climate. 2015;14:529-543. doi:10.1016/j.uclim.2015.09.009.

[2] Meyer L, Brinkman S, van Kesteren L, Leprince-Ringuet N, van Boxmeer F. IPCC, 2014: Climate Change 2014: Synthesis Report. Contribution of Working Groups I, II and III to the Fifth Assessment Report of thelntergovernmental Panel on Climate Change; 2014.

[3] Gutkind P. Congestion and Overcrowding: An African Urban Problem. Human Organization. 1960;19(3):129-134. doi:10.17730/humo.19.3.vk6892661p7414u4.

[4] Balsara JF. Problems of rapid urbanisation in India. Bombay, India: Popular Prakashan; 1964.

[5] Puppim de Oliveira JA, Doll CNH, Kurniawan TA, Geng Y, Kapshe $M$, Huisingh D. Promoting win-win situations in climate change mitigation, local environmental quality and development in Asian cities through co-benefits. Journal of Cleaner Production. 2013;58:1-6. doi:10.1016/j.jclepro.2013.08.011.

[6] Doll CN, Puppim de Oliveira JA. Urbanization and Climate CoBenefits: Implementation of win-win interventions in cities. Taylor \& Francis; 2017.

[7] Harrison P, Pearce F. AAAS atlas of population \& environment. University of California Press; 2000.

[8] Puppim de Oliveira JA, Doll CNH, Balaban O, Jiang P, Dreyfus $M$, Suwa $A$, et al. Green economy and governance in cities: assessing good governance in key urban economic processes. Journal of Cleaner Production. 2013;58:138-152. doi:10.1016/j.jclepro.2013.07.043.

[9] Balaban O, Puppim de Oliveira JA. Sustainable buildings for healthier cities: assessing the co-benefits of green buildings in Japan. Journal of Cleaner Production. 2017;163:S68-S78. doi:10.1016/j.jclepro.2016.01.086.

[10] Puppim de Oliveira JA. Learning how to align climate, environmental and development objectives in cities: lessons from the implementation of climate co-benefits initiatives in urban Asia. Journal of Cleaner Production. 2013;58:7-14. doi:10.1016/j.jclepro.2013.08.009.

[11] Transforming our world: The 2030 agenda for sustainable de-

velopment. New York, NY, USA: United Nations, Division for Sustainable Development Goals; 2015. Available from: https: //sustainabledevelopment.un.org/post2015/transformingourworld.

[12] McGranahan G, Satterthwaite D. Urbanisation: concepts and trends. IIED London; 2014.

[13] EMBARQ - The WRI Center for Sustainable Transport. "Global BRT Data-Worldwide and Key indicators per region". Available from: BRTdata.org.

[14] Gemzoe L. Copenhagen on foot: thirty years of planning and development. World Transport Policy and Practice. 2001;7(4):19-27.

[15] Roppongi H, Suwa A, Puppim de Oliveira JA. Innovating in sub-national climate policy: the mandatory emissions reduction scheme in Tokyo. Climate Policy. 2016;17(4):516-532. doi:10.1080/14693062.2015.1124749.

[16] Cui L, Shi J. Urbanization and its environmental effects in Shanghai, China. Urban Climate. 2012;2:1-15. doi:10.1016/j.uclim.2012.10.008.

[17] Hotta $Y$, Aoki-Suzuki C. Waste reduction and recycling initiatives in Japanese cities: Lessons from Yokohama and Kamakura. Waste Management \& Research. 2014 jul;32(9):857866. Available from: https://doi.org/10.1177\%2F0734242×14539721. doi:10.1177/0734242x14539721.

[18] Ahmad S, Balaban O, Doll CNH, Dreyfus M. Delhi revisited. Cities. 2013;31:641-653. doi:10.1016/j.cities.2012.12.006.

[19] Puppim de Oliveira JA. The implementation of climate change related policies at the subnational level: An analysis of three countries. Habitat International. 2009;33(3):253-259. doi:10.1016/j.habitatint.2008.10.006.

[20] Puppim de Oliveira JA. Intergovernmental relations for environmental governance: Cases of solid waste management and climate change in two Malaysian States. Journal of Environmental Management. 2019;233:481-488. doi:10.1016/j.jenvman.2018.11.097.

[21] Urbanization and development: Emerging futures. Nairobi, Kenya: UN-Habitat; 2016.

[22] Transformations for Sustainable Development: Promoting Environmental Sustainability in Asia and the Pacific. Bangkok, Thailand: United Nations Economic and Social Commission for Asia and the Pacific; 2016. 